How to Cite

Kumar, A. (2018). Indian railways catering: Jammu-New Delhi Duronto train. International Journal of Life Sciences \& Earth

Sciences, 1(1), 23-28. https://doi.org/10.31295/ijle.v1n1.10

\title{
Indian Railways Catering: Jammu-New Delhi Duronto Train
}

\author{
Alok Kumar \\ Amity University, Noida (U.P), India \\ Email: kumaralok1975@yahoo.co.in
}

\begin{abstract}
Indian Railways is one of the world's biggest modes of transportation of passenger transit in the world. More than 21 million people from varied culture \& tradition and socio-economic conditions travel by the Indian Railways daily. The conspicuous growth in the Indian economy over the last two decades has increased demand for all transport services, specifically land transport through road and rail. This paper is based on a case study conducted to observe food facility available on the premium train of Indian Railways- "Duronto" on an important tourism and pilgrim circuit of Jammu \& Kashmir connecting to India's capital-New Delhi. The findings of this paper highlight how Indian Railway \& IRCTC are still lacking behind and not able to provide even basic catering services to the passengers.

Keywords---catering, Indian railway, IRCTC, Jammu-New Delhi-Duronto, train.
\end{abstract}

\section{Introduction}

A landmark in the history of India Railway evoked on April 16, 1853, when it started its journey of $53 \mathrm{~km}$ between Mumbai to Thane. Today, it has one of the largest rail networks in the world with 65,808 km route kilometers of route length and 7,112 stations. It contributes a cheap and affordable means of transportation to millions of passengers, hence playing a dominant role in the social and the economic development of the country. Today, Indian Railway is serving over 23 million passengers every day. (https://en.wikipedia.org/wiki/Indian_Railways)

As a part of Indian Railways' wider organizational amend and to intensify its commerce and service capabilities in the areas of rail catering, tourism, hospitality and passenger amenities a corporate body, Indian Railways Catering And Tourism Corporation Limited (IRCTC) was incorporated on 27th September 1999 under the Companies Act 1956 as a Government company. This company attains the Certificate of commencement of Business on 2nd December 1999. The full-fledged functioning of the Corporation started on 1st August 2001 (Priyanka G. et al., 2012). IRCTC is connecting India in more than one way. Thus, the primary objective of the IRCTC is to provide a single window-service for hospitality, travel and tourism products. The catering business of Indian Railways is estimated to be around Rs 20,620 crore, which is nearly \$3 billion in the year 2014-15 (Economic Times, 2015).

The passengers traveling serve as the broad diversity of the country - regional diversity, cultural diversity and financial diversity. Due to the vast diversity of the country, food cuisine changes as one travels from one region to another. The catering services providers have to take into account the diversity of the passengers and provide services that would be appreciable by all. However, there are many faults in the planning and managing of the system which leads to consumer dissatisfaction (Patil. P, July 2012).

\section{Objective}

To study Indian Railways, IRCTC \& its catering services available on Jammu- Delhi, Duronto train. 


\section{Research Method}

a) Primary sources

To conduct the study, a tour was undertaken on Jammu -Delhi Duronto train. The observation /experience of food services \& options available to the travelers on this important tourism sector and a premium train connecting India's capital- New Delhi is highlighted in this case study.

b) Secondary sources

To carry out literature review about Indian Railways, its catering services, and IRCTC; the combination of following was used-

a) Books b) Journals c) Magazines/Periodicals d) News Paper e) Report Published by various Government \& Non-Government agencies and f) Useful internet websites.

\section{Review of Literature}

Indian Railway Catering and Tourism Corporation Ltd. (IRCTC) is a Public Sector Enterprise under Ministry of Railways. IRCTC was incorporated on 27th September, 1999 as an extended arm of the Indian Railways to upgrade, professionalize and manage the catering and hospitality services at stations, on trains and other locations and to promote domestic and international tourism through development of budget hotels, special tour packages, information \& commercial publicity and global reservation systems. Company's revenue from Catering increased to `296.42 crores, as compared to `280.83 crores in the year 2013-14 and Revenue from licensee catering increased to 69.79 crores as against $` 26.89$ crores in the year 2013-14. Under Election Special trains, meals in 319 trains and in more than 1000 splinter coaches were provided, all through the assembly elections in the states of Haryana, Maharashtra, J\&K and Jharkhand and also for bye-elections in West Bengal. Overall, 17 lakh meals worth 20 crores were supplied. (Annual Report 2014-15)

The corporation has made significant progress in travel and tourism segment of the business. IRCTC as a pioneer in this sector has established itself in providing a wide range of products and services to meet the requirements of different segments of tourists. These include Bharat Darshan tourist trains, State Special Tourist trains, Educational Tours, Buddhist Circuit Special Train, Maharajas' Express, Rail and Land Tour Packages, Chartered Trains \& Coaches, RTP with Charter Trains \& Coaches, Hill Charters, Luxury Tourist Train, Cab Rental Services, LTC service, Inbound \& Outbound packages, On-line hotel booking services, Online Air ticketing, and Corporate Travel Services. Travel \& Tourism Business of IRCTC generated an income of `362.37 Crore in the year 2014-15 as compared to to 324.14 crore in the year 2013-14 recording a growth of $11.79 \%$. During the year, the tourism segment generated an income of `362.37 crores as compared to `324.14 in previous year thereby registering a growth of $11.79 \%$. You will be glad to know that Tourism segment, for the first time, earned the profit amounting to 25.28 crores. The turnover of this segment has almost double due to significant strides made in domestic tourism. The total production of Rail Neer plants was 11.95 crores bottles during the year 2014-15 as against total production of 10.98 crores bottles in a previous year. During the year, the Company achieved a turnover of 95.38 crores for this segment (www.irctc.com)

Pantry cars occupy an important place in the catering system of the Railways by serving the onboard passengers of long-distance trains. While discharging its mandate, the Company has made a significant mark in its passengerservices oriented business lines like setting up of Food Plazas on Railway premises, 'Railneer', Rail Tour Packages and 'Internet Ticketing' bringing a great deal of professionalism into the operations. In addition to above, IRCTC is managing on Board Catering Services in Rajdhani / Shatabdi / Duronto and Mail / Express Trains and Static Catering Units such as Refreshment Rooms, AVMs, Book Stalls, Milk Stalls, Ice Cream Stalls, Petha \& Peda Stalls etc. across the Indian Railway Network.

\section{Organization Structure}

Corporate Office of IRCTC is situated at New Delhi, which is headed by the Managing Director. Managing Director is being assisted by three Directors, Director (Catering Services), Director (Tourism \& Marketing) and Director (Finance) and nine Group General Managers.

For smooth operations of the business across all over the country, five Zonal Offices are working at Delhi, Kolkata, Mumbai, Chennai \& Secunderabad. South Zone Office is headed by Regional Director and all other Zonal Offices are headed by Group General Managers. All Group General Managers have vast experience of working in 
Indian Railways. These Zonal Offices are assisted by ten Regional Offices at Lucknow, Chandigarh, Jaipur, Bhubaneshwar, Guwahati, Patna, Bhopal, Ahmedabad, Bangalore, and Ernakulam, which are headed by Chief Regional Managers / Regional Managers. (http://www.irctc.com/Company_Profile.html)

\section{Results and Analysis}

\section{IRCTC's main business activities}

On Board Catering Services and Static catering units on the Indian Railway Network

Hospitality Services covers onboard catering services in the trains, catering services at stations through stalls, food plazas/fast food units \& Automatic Vending Machines commissioned at A, B \& C class of Railway stations. During the year, IRCTC handed over catering services of 01 BBS-NDLS Rajdhani to East Coast Railway (ECoR) and 3 Mail/Express trains (Kerala Express, Thirukkural Express \& Vivek Express) to Southern Railway and Northeast Frontier Railway. IRCTC managed onboard catering services in 75 pairs of Premium trains through the award of temporary licenses \& departmental operations and operated more than 2000 trips. IRCTC also managed onboard catering services in 18 pairs of Mail/Express trains through the award of temporary licenses. IRCTC operated 17 Durontos, 06 Rajdhanis, 03 Shatabdi and 10 Mail Express trains departmentally. During the year, the following Jan Ahaars, Refreshment Rooms and Minor Units (Stalls, Trolleys etc.), operated by IRCTC, were handed over to Zonal Railways.

Table 1

IRCTC Handed Over

\begin{tabular}{lll}
\hline Particular & Handed Over & Left with IRCTC \\
\hline Jan Ahaars & 1 & 13 \\
Refreshment Rooms & 2 & 5 \\
Minor Units (Stalls, Trolleys etc.) & 5 & 130 \\
\hline
\end{tabular}

Source: IRCTC Annual Report 2014-15

During the year, the Company commissioned 43 Food Plazas/Fast Food Units, making the total number of operational units to 191 . The Company also awarded 41 units at an annual license fee of ' 22.98 crores during 201415. IRCTC has ventured into retail format business by opening Food Kiosks at DMRC stations across Delhi-NCR. IRCTC has 63 operational Food Kiosk on DMRC network across Delhi-NCR. The kiosks dispense branded prepacked food \& beverages and pre-cooked food procured from IRCTC Central Kitchen, Noida and Railneer for packaged drinking water. At present, IRCTC is operating 191 Food Plazas and Fast Food units over Indian Railways. The annual earning from these units is 31.24 crore. (http://www.irctc.com/Company_Profile.html)

\section{Duronto Express}

Duronto Express is a category of long-distance nonstop trains run by the Indian Railways. These trains do not have any ticketing stops between the origin and the destination."Duronto" means "ends at far-flung destination" in the Bengali language. These trains' coaches have characteristic yellow-green livery. Duronto Express services connect the several metros and major state capitals of India. These trains are faster than or as fast as Rajdhani and Shatabdi trains.

The Duronto Expresses are one of the fastest trains in India. These trains run faster than Rajdhani Express trains which hold the record of the fastest long-distance trains in India. This has been made possible as these trains, unlike the Rajdhani Express, do not have any intermediate stops and run in much the same speed clocked by Rajdhani.

\section{Delhi SaraiRohilla Jammu Tawi Duronto Express}

\begin{tabular}{ll}
\hline \multicolumn{1}{c}{ Overview } \\
\hline Service type & Superfast, Duronto Express \\
First service & 1 April 2010 \\
Current & Northern Railways
\end{tabular}




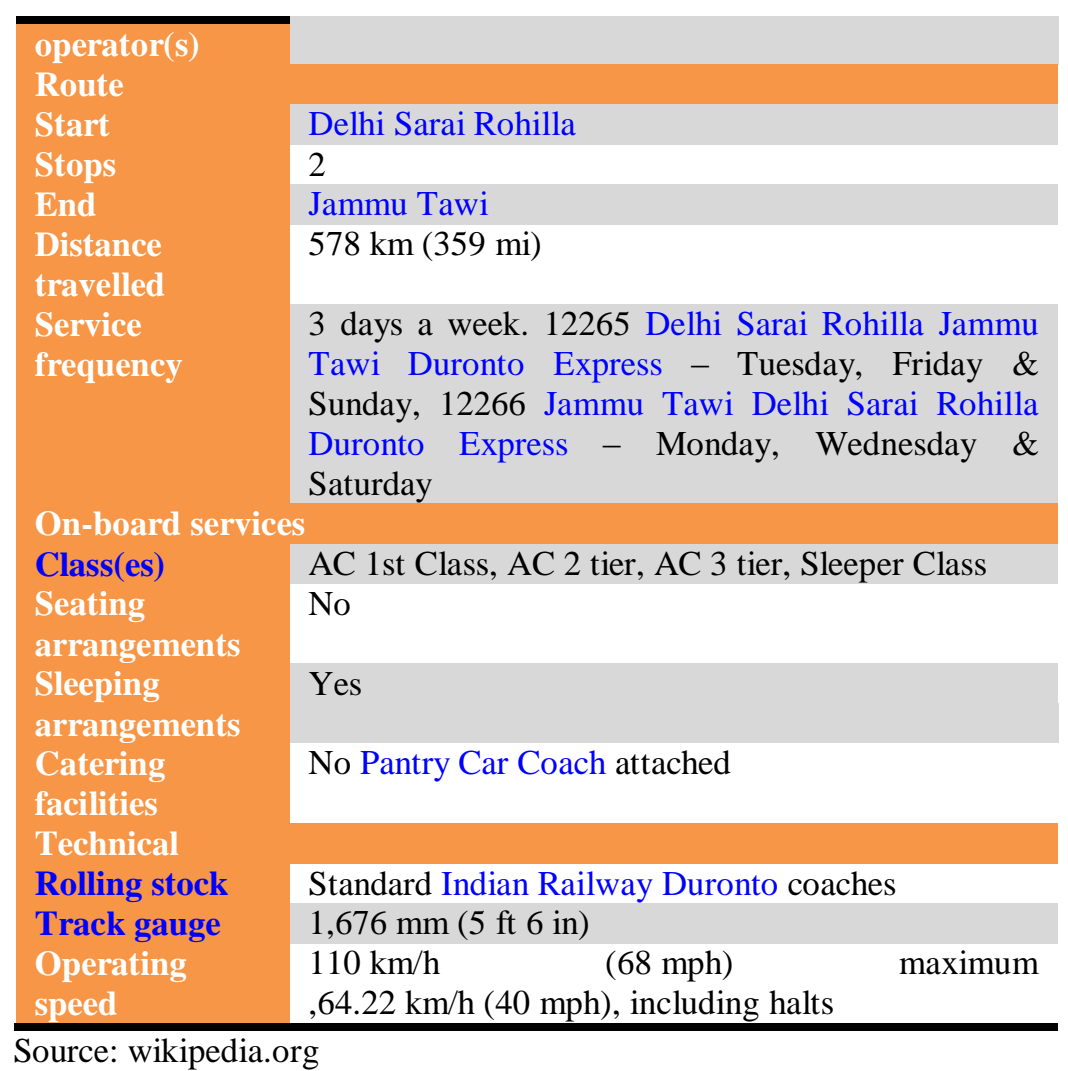

\section{IRCTC E-Catering}

The Company endeavor into a new business of providing meals of passengers' choice(s) at seat/berth under "Ecatering". The project was started in a limited way on Delhi- Jammu Tawi and Delhi-Amritsar route. Subsequently, 14 trains without pantry cars were identified with 8 locations (Food Plazas/Fast Food Units/Jan Ahaar) for delivery of pre-ordered meals to the train passengers. Earlier, the services were provided through booking of meals on phone, and thereafter, the facility has been extended to book meals through website www.ecatering.irctc.co.in also. With the date of its launch on 25 September 2014 and till 31 March 2015, the number of trains was increased from 14 to 2015. However, at present, 1516 trains are covered under E-Catering. Railway Board has recently approved inclusion of 1319 additional trains for e-catering. All the above trains are now live for booking of meals in the year 2015-16. IRCTC has also roped in reputed brands such as Dominos', Pizza Hut, KFC, Punjab Grill, Copper Chimney, and Idli.com to provide e-catering services in various trains. (Annual Report 2104-15)

\section{Jammu-Delhi Duronto- A Case Study}

We conducted our journey from Jammu in Duronto Express in the month of February 2016. It is one of the fastest trains to Delhi from Jammu. We were traveling in AC 3 Tier which is more in number and usually preferred by a normal tourist visiting this part of the country either for leisure tourism or pilgrimage. The train's third AC compartments are very congested and if you happen to be on side berth then you are in for a great trouble. We had expectations of the services at least equivalent to Rajdhani. But it was not even near to services in the trains other than Rajdhani.

Apparently, the train does not provide meal or drinking water, since it is an overnight train and we were not aware of the fact this train doesn't have pantry car so no food was carried. Even traveler returning from Vaishno Devi after pilgrimage also cannot afford to do so. We tried to find out whether we can still get something to eat. The train starts from Jammu Tawi at.19.25 hours and runs non-stop to its destination SaraiRohilla Station, Delhi where it arrives at 04.00 hours. Technically, since the train starts before dinner time, it should serve dinner to the passengers as in other Duronto trains, and the cost of the meals could be included in the cost of the ticket. Then we decided to wait till Ludhiana station to come because at this station train has stoppage for about 10 mins. Meanwhile, we 
thought to order some food online through IRCTC portal for online delivering food to stations but that attempt was also a great failure. As we called the Toll-free number given on the website which was not answered and was trying to order online but nothing was working (www.hindustantimes.com). Lately, when the train arrives at Ludhiana at its scheduled time then we got some snacks to have it as a form of dinner. But the question is why haven't they included the cost of meals in the total fare when the train leaves its originating station i.e. Jammu Tawi much before dinnertime. Had dinner and water been served, wouldn't it have been apt for the passengers who, by the way, are paying more than any superfast train doing the same distance? And a Duronto not serving meals and water is by far not the best advertisement for a showpiece-train. Rather, instead of the Jammu-Delhi Duronto, they could have just added another Jammu-Delhi Superfast. Last not least, all the other Duronto's having a pantry-car on board and serving meals to the passengers, so why can't the same function should be implemented in this Duronto as well. Adding to this there was no proper waste disposal system and cleanliness in the toilets of this train and AC was not working at all in the coach during the whole night of the journey. Overall, it was a journey with a lot of expectations with the name of "Duronto" but it was not at par.

\section{Conclusion}

It can be concluded from above discussion that no services are offered by the IRCTC on this route \& Duronto train. While IRCTC is the only railway service provider in a country, it enjoys $100 \%$ ownership in the railway travel market and due to this reason the quality of the catering services are not up to the relevant standard, which needs to make immense improvement not only in its customer service but also in the quality of food \& water they provide to its passenger. The Railway Ministry has to take various measures to improve the services by properly peruse the sorrow of the passengers routinely. The Railways has to know the needs and expectations of the passengers with the help of effective functioning of their team or by setting up different Grievance handling desks at different stations. The Railway Ministry could also be responsible to monitor whether IRCTC E-Catering toll-free numbers are properly working and the passengers are able to utilize the services as promised by the IRCTC E-Catering Unit. Thus, if we talk about the Delhi-Jammu Duronto train the railway could include the cost of meals in the total fare as the train actually leaves its originating station i.e. Jammu Tawi much before dinner-time and the kind of passengers those who are travelling most of them are either pilgrims, tourists or defense personnel so it becomes more important to serve the food for them as they are not a kind of passengers who can't carry their own food from home. Hence, pantry car should be attached to the train so that complete catering services are available to the passengers. And as per information available on Indian railway website; almost all Duronto have pantry cars and they provide highquality catering services to the passengers. IRCTC is the service provider to Indian Railway it can hire a good local vendor who can provide a quality product for foods and beverages at a reasonable cost. Thus, by doing this they can provide better catering facilities in every train including Delhi-Jammu Duronto for the growth of tourism.

\section{Acknowledgments}

The author would like to thank the editors for their valuable time and advice. 


\section{References}

Jain, P., Jain, A., Singhai, R., \& Jain, S. (2017). Effect of Biodegradation and Non-Degradable Substances in Environment. International Journal of Life Sciences (IJLS), 1(1), 58-64.

Punitha, P. S. (2017). Improving the Management Structure of Justice Gopal Singh Public Charitable Trust, raising funds for a Multi-specialty and Cancer Hospital through crowd-funding \& formulating the structure of an NGO that channelizes CSR work of companies.

Sahu, G. P., \& Singh, M. (2017, November). Factors Influencing Consumer's Behavioral Intention to Adopt IRCTC Connect Mobile Application. In Conference on e-Business, e-Services and e-Society (pp. 3-15). Springer, Cham.

Saxena, A. (2017). The Impact of Nutrition on the Overall Quality of Life Adolescent Girls is Living Across the City of Kota. International Journal of Life Sciences (IJLS), 1(1), 40-48.

Shahaida, P., Rajashekar, H., \& Nargundkar, R. (2009). A conceptual model of brand-building for B-schools: An Indian perspective. International Journal of Commerce and Management, 19(1), 58-71.

Sutapa, I. K., Sutapa, I. N., \& Susila, I. N. D. (2017). Implementation of Active Rest in Participatory Ergonomics Decrease Workload and Women Musculoskeletal Complaints of Parking in Mall Ramayana Denpasar. International Journal of Life Sciences (IJLS), 1(2), 48-54. 